\title{
INTEGRATED 3D SURVEY FOR THE DOCUMENTATION AND VISUALIZATION OF A ROCK-CUT UNDERGROUND BUILT HERITAGE
}

\author{
G. D’Agostino ${ }^{1}$, M. Figuera², G. Russo ${ }^{1}$, M. Galizia ${ }^{1}$, P. M. Militello ${ }^{2}$ \\ ${ }^{1}$ Department of Civil Engineering and Architecture, University of Catania, Via Santa Sofia n. 64 95123, Catania, Italy \\ graziana.dagostino@unict.it, gloria.russo@studium.unict.it,mgalizia@dau.unict.it \\ ${ }^{2}$ Department of Human Science, University of Catania, Piazza Dante n. 24 95124, Catania, Italy \\ (marianna.figuera, milipi)@unict.it
}

Commission II

KEY WORDS: Underground Built Heritage, Narrow Spaces, Hypogeum, Archaeological rock-cut Heritage, Digital Survey, Mobile Mapping, Laser Scanning, Photogrammetry.

\begin{abstract}
:
The research presented here is part of an on-going research focused on the 3D documentation of rock-cut Underground Built Heritage with a complex morphology and characterised by narrow spaces, the Hypogeum of Calaforno (province of Ragusa, Sicily). It is one of the most interesting prehistoric monuments in Sicily in terms of size and unique rock-cut architecture. Various digital techniques have been tested over the years on the site, to represent its spatiality, such as Laser Scanner and Structure from Motion. The proposed methodological approach for the knowledge and the documentation of this archaeological site is based on an interdisciplinary approach involving archaeological and engineering disciplines. This paper focuses on the use of expeditious techniques such as iMMS (indoor Mobile Mapping Systems) based on SLAM (Simultaneous Localization and Mapping) and on the comparison of different surveying equipment in order to verify data quality and accuracy, as well as the inherent advantages of using one technology over another in relation to the characteristics of the site. Through the global verification of TLS and SLAM model reliability, we maintain that such research can contribute to enriching the protocols surrounding the archaeological investigation of sites characterized by complex morphology, irregular surfaces, narrow spaces, specific chromatic features, scarce or total lack of lighting, and physical obstacles.
\end{abstract}

\section{INTRODUCTION}

The knowledge and documentation of complex archaeological heritage requires detailed and analytical metric investigation, which integrated digital surveying techniques have greatly improved.

The 3D digitization of cultural heritage for visualization, valorization, monitoring, investigation, and documentation purposes is now a consolidated practice in terms of practical application during the acquisition phase and in relation to the post-processing of the data and models obtained. Today, a multitude of 3D metric acquisition techniques and equipment are available, which differ in terms of function, size, acquisition time, accuracy level, and quality of the output model. For these reasons, it is important to understand their potential, limits, and applicability in relation to specific contexts and characteristics (Di Stefano et al., 2021). Such investigation should involve the application and comparison of different techniques and equipment at the same site. This research intends to contribute to the experimentation and comparison of different 3D survey techniques applied to a complex rock-cut architecture; an interesting case study with special morphological attributes. Underground Built Heritage (UBH) is a particular segment of cultural heritage that is often insufficiently documented, poorly valorised and rarely visited (Pace, 2019). The work presented here is part of on-going research focused on the $3 \mathrm{D}$ documentation of underground environments with complex morphologies (D'Agostino et al., 2021b). The Hypogeum of Calaforno (province of Ragusa, Sicily) is one of the most interesting prehistoric monuments in Sicily in terms of size and unique rock-cut architecture. It is characterised by a total lack of lighting, numerous very narrow rooms connected by small holes, and an irregular, inclined layout.

In recent years, several research groups performed digital surveys of underground archaeological sites (Ebolese et al., 2019; Perfetti et al., 2018) to develop digital documentation and 3D representations of the morphologically complex surfaces. The studies revealed how illumination, narrow spaces, accessibility, and irregular morphologies can significantly condition surveying strategies for quarries, caves and underground environments. The on-going research has already tested and compared Terrestrial Laser Scanner (TLS) and Structure from Motion (SFM) survey technologies to evaluate their efficacy. This paper focuses on the use and reliability of a recent expeditious technique, the indoor Mobile Mapping Systems (iMMS) based on Simultaneous Localization and Mapping (SLAM) technology. The experimentation proved fundamental for the resolution of many scientific problems caused by various technical issues that hampered the first survey, made with traditional methods (Guzzardi, 1980), as well as for identifying previously undiscovered architectural elements, traces of work until now ignored and chronological articulations, useful to verify if the Hypogeum was excavated in one single period or in many phases. We were also able to record the current state of preservation in enough detail to be able to adequately monitor any future degradation. The research has also provoked some reflection on the relationship between the possibilities offered by the state-ofthe-art equipment and the intelligibility and usefulness of 3D data obtained for the visualization and documentation of surveyed heritage. 


\section{RELATED WORKS}

\subsection{D Survey of Underground Built Heritage}

Survey and documentation are fundamental processes for understanding, visualizing, and preserving $\mathrm{UBH}$, and these issues have been the subject of concerted interest from several research groups.

In recent years, several digital surveys on UBH have been performed and studied (Alessandri et al., 2020; Saulli et al., 2018) with the aim of developing digital graphic and volumetric representations of the morphological complexity of the surfaces. The integration of TLS and SFM surveying techniques has found wide implementation in their ability to expand and complete the $3 \mathrm{D}$ data of individual surveying techniques in underground environments, such as in the study of the Bat Cave of the Pantalica Nature Reserve (province of Ragusa, Sicily), where lighting conditions and site morphology heavily influenced insitu survey activities (Aiello et al., 2019). This integration is particularly useful for the acquisition of chromatic data of underground environments with poor lighting, as shown in the survey of the Hypogeum of Crispia Salvia in Marsala (province of Trapani, Sicily) (Tanasi et al., 2021) and in the survey of the Palazzo Campana caves in Osimo (province of Ancona, Marche) (Clini et al., 2019), which house frescoes and bas-reliefs. The use of TLS in UBH is complicated by narrow spaces and limited accessibility, and the high number of scans required for extensive and morphologically complex sites significantly increases surveying and data processing times. The alternative SfM technique is sensitive to inconsistent or insufficient lighting conditions. The choice of the most appropriate surveying technique and corresponding post-processing techniques therefore depend largely on the purpose of the three-dimensional reconstruction, as demonstrated by the research conducted on the underground passages in the First World War fortifications in the Trentino region (Rodríguez-Gonzálvez et al., 2015) and on the Octhiná Aragonite Cave in Slovakia (Pukanská et al., 2020).

\subsection{SLAM Technologies}

The use of SLAM-based surveying techniques can be useful in caves, quarries, underground sites thanks to the easy manoeuvrability of the instruments and the speed of data acquisition and processing (Sammartano and Spanò, 2018).

A comparison between TLS and MMS survey techniques shows that the former guarantees higher geometric accuracy of the $3 \mathrm{D}$ point cloud, while instrument manoeuvrability, data acquisition, and processing time represent the overriding factors for determining the appropriate survey technique for narrow, poorly accessible and low-light environments (Giordan et al., 2021, Salgues et al., 2020). SLAM technology facilitates operator movement and can survey the $3 \mathrm{D}$ environment even in the absence of light, as opposed to photogrammetry. Data acquisition and processing times involving SLAM technology are significantly reduced compared to both TLS and SfM surveys (Mandelli et al., 2018, Teppati Losè et al., 2021).

In comparison to TLS, point clouds acquired by SLAM technology suffer lower point density and higher noise, and may present trajectory drift issues, depending on the instrumentation used and the survey design (La Russa et al., 2021). Comparing different scans of the same object, larger trajectory paths and shooting times deliver higher point cloud density and greater readability of the data (Dell'Amico, 2021).

SLAM system survey can guarantee 3D accuracy for 1:200 and 1:100 scale geometric representations, while survey through a static laser scanner is certainly necessary for obtaining accurate architectural details (Di Stefano et al., 2021, Piniotis et al., 2020, Chiabrando et al., 2018).

\section{CASE STUDY}

The Hypogeum of Calaforno (province of Ragusa, Sicily) is the case study chosen for the special characteristics that render it one of the most important prehistoric monuments in Sicily. Its peculiarities lie not only in the size of the monument, but also in the morphological features that offer a unique representation of rock-cut architecture (Figuera, 2018; Militello, 2021).

The Hypogeum is characterized by an irregular, $100 \mathrm{~m} \mathrm{ca}$. route consisting of 35 rooms and a monumental entrance formed by a complex external corridor (so called dromos) built from large blocks, leading to a main entrance room (ca. $12 \times 4 \mathrm{~m}$ ) carved into the rock, acting as a kind of vestibule for the true funerary chambers. All the rooms are circular in plan and vary in diameter from 1.5 to $3 \mathrm{~m}$ and height from 1.6 to $1.8 \mathrm{~m}$. In the geometric and morphological features of the Hypogeum, it is possible to distinguish sections with different design concepts. The first section consists of smaller and lower rooms (1-9) arranged along a serpentine route. The central section is formed by rooms aligned and organized into three axial groups $(11-14 ; 15-21 ; 28$ 30 ) (Figure 1) connected by rooms arranged in a ring shape (22$25)$, while the last section is oriented differently $(31-35)$. Other rooms functioning as connecting spaces $(10,26-27)$ are larger and differ in shape. Besides the general morphology of the monument, there are many special aspects that are often difficult to detect and document. Among these are the room openings with differing shape and size, the mobile lithic elements, slabs, and blocks, scattered throughout the Hypogeum, the traces of work on the ceilings and walls, the niches for the oil lamps, as well as other features. The relevance of these elements, some showing evidence of subsequent reworking, is linked to the archaeological interpretation of the monument and its function over time.

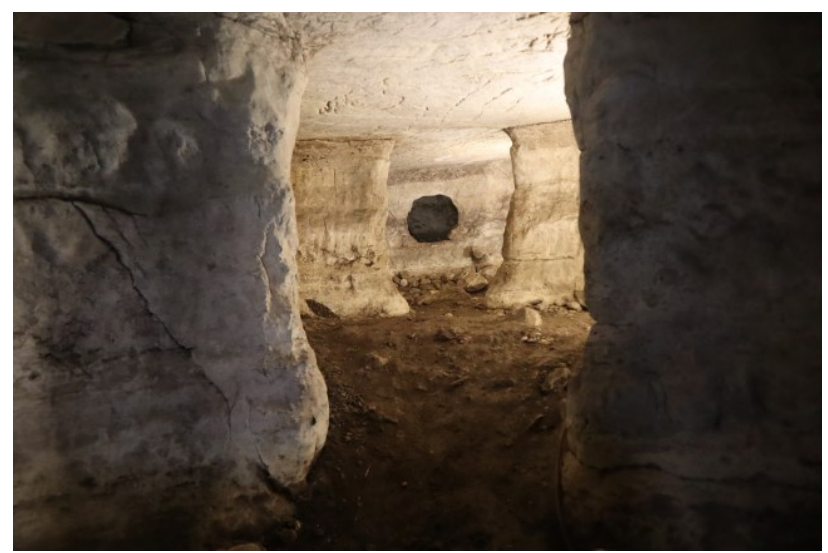

Figure 1. Enfilade of rooms 19, 20, 21

The Hypogeum had different uses interspersed with periods of neglect. Its construction spanned from the Late Copper Age (ca. 2700-2200 BC) to the Early and Middle Bronze Age (ca. 2200$1250 \mathrm{BC}$ ), and was used until the final collapse of the entrance (ca. $1050 \mathrm{AD}$ ). It was initially used as a burial site, later becoming a ritual area to honour ancestors, and finally partially reoccupied as a cemetery and an industrial and stockage area or an animal shelter.

The Hypogeum was identified in the 1970s by Lorenzo Guzzardi (Guzzardi, 1980) but, notwithstanding its special nature, did not undergo systematic investigation until 2013, when archaeological research recommenced under the direction of Pietro Militello of the University of Catania (Militello and Di 
Stefano, 2015; Militello, 2021) and, outside the Hypogeum, under the direction of S. Scerra and A.M. Sammito of the Soprintendenza BB.CC.AA. Ragusa (Militello et al., 2018). Research activities focused on the archaeological excavation inside the Hypogeum and on many traditional survey activities performed to integrate the only edited representation by Guzzardi (shown in Figure 2), which illustrates the geometric and morphological characteristics of the planimetric system. The traditional survey methods have proven to be inadequate in terms of depicting rock cut or "a-structural" architectures. Calaforno presents several difficulties such as the lack of relevant points of discontinuity and the consequent identification of section planes necessary for identifying the layout and understanding the monument in general. Moreover, there are practical problems due to the narrow spaces, lack of light, restricted room spaces, the serpentine arrangements and the presence of water in some rooms (Figuera, in press). This is especially true for rooms 13-14-15-16, where the research activity remained incomplete due to access issues involving the presence of blocks and backfill, in addition to their limited size.

Therefore, it was considered appropriate to integrate the research work with digital solutions to realize a comprehensive new survey of the monument and to verify large quantities of data in order to solve a series of archaeological problems.

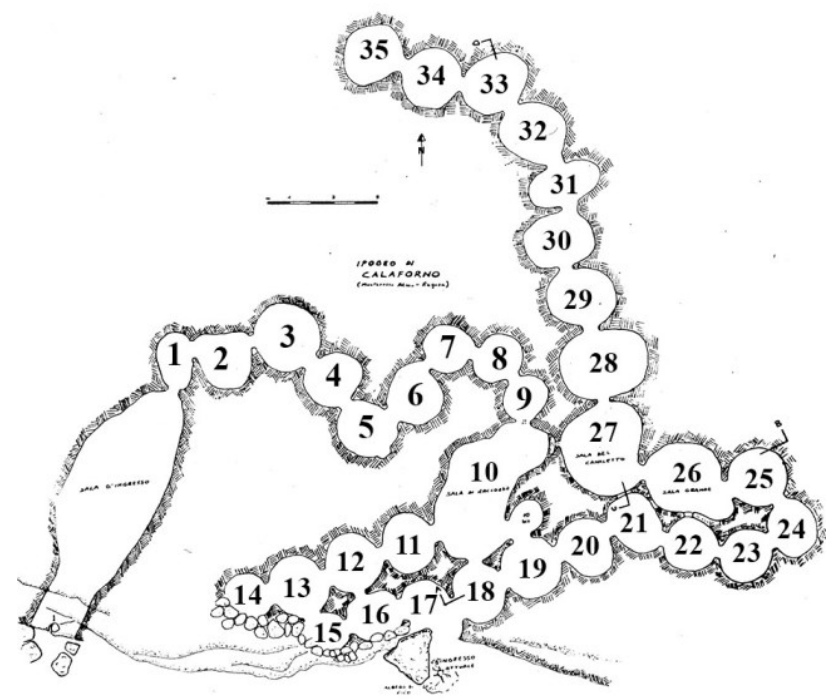

Figure 2. First survey 2D representation by Guzzardi 1980.

\section{METHODOLOGY}

The experimentation aims primarily to evaluate the effectiveness and critical issues of the Mobile Laser Scanner mapping system based on Simultaneous Localization and Mapping (SLAM) BLK2GO by Leica Geosystem. This followed testing of other digital surveying techniques and instruments: the Leica Geosystem P30 laser scanner for the survey of the entire Hypogeum (2017, 2021), the Leica BLK360 Imaging Laser Scanner for the external structures (2021), and the use of the GoPro Black Hero 6 for the photogrammetric survey of one of the smaller rooms (Tucci, 2017).

The proposed methodology for the documentation and visualization of this archaeological area is based on an interdisciplinary approach involving archaeological and engineering disciplines. Working at a site of high cultural relevance requires relevant expertise and constant dialogue between the disciplines involved to determine the historical use of the area and the reasons for its current geomorphological status, as well as to design the workflow and methodology to be implemented. The Hypogeum is characterised by a height difference of $5 \%$ from north to south and $2 \%$ from west to east. Due to the difficulty of identifying horizontal section planes, it does not lend itself to a direct survey approach. It is also subject to practical issues involving narrow spaces, the serpentine route of the rooms, and lighting conditions. It was therefore decided in 2017 to test digital surveying techniques for acquiring and representing its distinctive spatial configurations. The special morphological characteristics of the site made it necessary to primarily use a Laser Scanner for the 3D digital surveying. The use of a TLS is now consolidated practice due to the quality of the data obtained in different contexts, and the TLS point cloud remains therefore essential as a reference model in terms of point quantity, point density, restitution scale, noise level, and acquisition and processing time. This research offers the possibility of comparing different surveying equipment in order to verify data quality and accuracy, as well as the inherent advantages of using one technology over another in relation to the characteristics of the site. As recent iMMS technologies offer more expeditious capabilities for surveying highly complex environments, we decided to test them for surveying the underground environments in the case study in 2021. The workflow was organised along the following steps (Di Stefano et al., 2021; Tucci et al., 2018):

archaeological investigation of the site;

post-processing of the P30 point cloud from the previous TLS digital survey;

- $\quad$ testing the iMMS digital survey of the underground area (acquisition and post-processing); georeferencing of both point clouds; metric and/or visual comparison between P30 and BLK2GO point clouds of rooms 1 to 35 ;

metric and/or visual comparison between P30 and BLK2GO point clouds of room 23;

metric and/or visual comparison between P30 and GoPro point clouds of room 23;

Current research is aimed at developing and experimenting workflows to obtain 3D models of appropriate quality through digital survey techniques that allow the geometric data to be acquired more expeditiously.

\section{DIGITAL SURVEY AND PROCESSING}

The digital survey activity for the 3D acquisition of the hypogeous area of the Calaforno site was conducted in different temporal phases and with different equipment.

The first experience took place between 2017 and 2019 using the Leica P30 TLS (scan rate: 1 million pts/sec, accuracy: $3 \mathrm{~mm}$ at $50 \mathrm{~m} ; 6 \mathrm{~mm}$ at $100 \mathrm{~m}$, ranges: up to $270 \mathrm{~m}$, size: $238 \mathrm{~mm} \times 358 \mathrm{~mm}$ $\times 395 \mathrm{~mm}$, weight: $12.25 \mathrm{~kg}$ ). It was impossible to survey rooms $2,3,4,5,6,11$, and 12 at the time due to the presence of water. This problem was solved when research activities resumed in 2020 and the survey was completed with the same instrumentation.

Contextually, the 2020 survey of the dromos and the external structures of the Hypogeum was integrated using the Leica BLK360 Imaging Laser Scanner (scan rate: $360.000 \mathrm{pts} / \mathrm{sec}$, accuracy: $6 \mathrm{~mm}$ at $10 \mathrm{~m} / 8 \mathrm{~mm}$ at $20 \mathrm{~m}$, ranges: up to $60 \mathrm{~m}$, size: H $165 \mathrm{~mm}$, D $100 \mathrm{~mm}$, weight: $1 \mathrm{~kg}$ ). The final P30-BLK360 numerical model is about 540 million points (Figure 3).

The workflow described in the methodology was applied to the articulated route of the 35 rooms of the Hypogeum, which suits the research themes presented here in particularly well. The size of the underground area and the narrow dimensions of each room made it necessary to set the P30 TLS scanning resolution to 6.2 $\mathrm{mm}$ at $10 \mathrm{~m}$ to obtain an appropriate overlap between the 
different scans and an accurate numerical model. Moreover, due to the total lack of lighting and the difficulty of introducing uniform artificial illumination, it was not possible to obtain chromatic RBG information regarding the interior rooms.

A future objective of the research is to create a virtual tour of the Hypogeum, which is difficult for the public to access. The SFM survey was therefore also tested to obtain a polygonal model with a high RGB value. A preliminary test was conducted in room 23 using the wide-angle lenses of GoPro Black Hero 5 Action Cam (size: $62.3 \mathrm{~mm} \times 44,9 \mathrm{~mm} \times 32 \mathrm{~mm}$, weight: $118 \mathrm{~g}$, FOV $130^{\circ}$ ) (D'Agostino et al., 2021a). This room was chosen for its relatively small dimensions.

Due to the size of the P30 TLS and the presence of blocks and backfill causing access difficulties, the overall numerical model is missing rooms 13,14, 15 and 16, which are depicted in Guzzardi's representation.
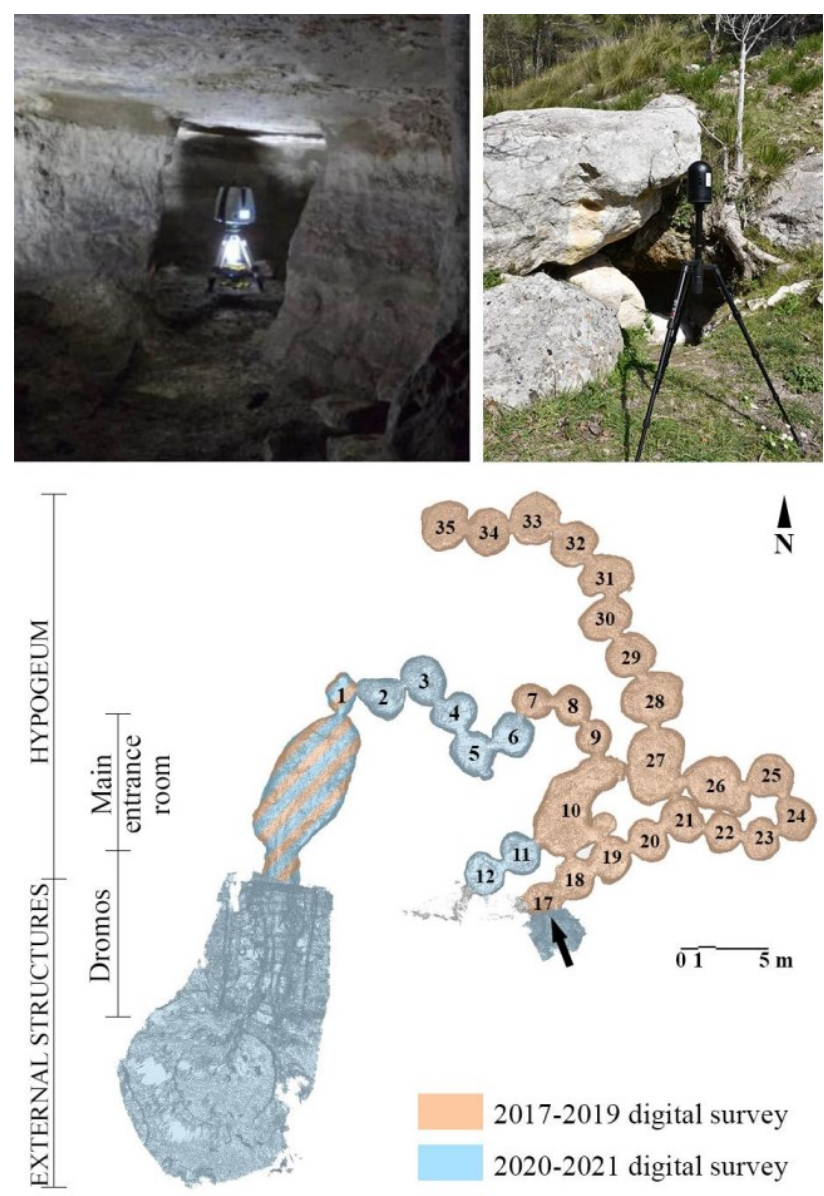

Figure 3. On site acquisition by P30-BLK360 LS and top view of the final laser scanner point cloud.

\subsection{Tested Mobile Mapping System}

In 2021, the SLAM technique was tested for the survey of all 35 rooms. The BLK2GO (scan rate: $420,000 \mathrm{pts} / \mathrm{sec}$, ranges: up to $25 \mathrm{~m}$, size: H $279 \mathrm{~mm}$, D $80 \mathrm{~mm}$, weight: $775 \mathrm{~g}$ ) is a handheld device that uses a real-time LIDAR scanning and GrandSLAM technology. It represents a combination of LiDAR SLAM, Visual SLAM, and an IMU (Inertial Measurement Unit) technologies. The computation of instrument position and movement are based on LIDAR analyses of the surfaces, three cameras to identify similarities between sequential images and IMU movement sensing. In addition to using the cameras to identify points and correct the trajectory, the BLK2GO is able to work in total darkness as it can recognise the geometry of the acquired objects, which is part of the reason why this device was chosen for the survey of the morphologically complex and scarcely illuminated Hypogeum.

The success of the acquisition process strongly depends on several factors, including the operator's walking speed, the inclination angle of the instrument, and the width of the surveyed space. Considering that the operator is obliged to walk in a crouched position, the maximum walking speed never exceeded $1 \mathrm{~m} / \mathrm{s}$. The field of view of the BLK2GO removed the need for multiple passes, but roundtrips are preferred to avoid drift error propagation. The acquisition route was divided it into two paths based on the configuration of the environment. Problems related to drift errors can also be remedied by concluding the acquisition path at the same location where device initialisation is performed. From the two routes undertaken in Figure 4, only the second route in blu did not start and end in the same position.
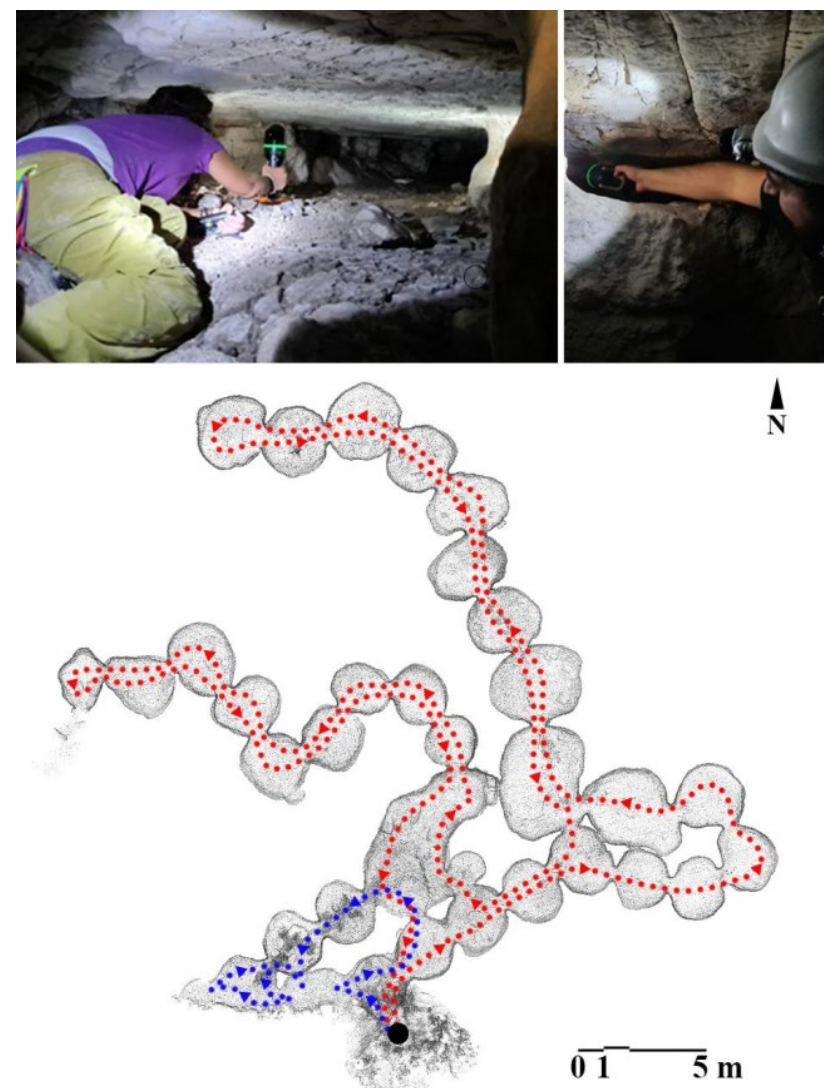

Figure 4. BLK2GO acquisition paths: red path (length: $147 \mathrm{~m}$., time: approx. $18 \mathrm{~min}$.), blue path (length: 25, time: approx. 6 min.).

The BLK2GO numerical model is about 4 million points. Thanks to the BLK2GO, it was finally possible to survey rooms 13,14 and 15-16. These rooms, not yet fully excavated, have a free height of about $35 \mathrm{~cm}$, so it was impossible to use the P30 or the BLK360 TLS in these interiors (Figure 5). This made it possible to digitally implement the existing graphic documentation of these rooms, which are difficult to survey in traditional method. 


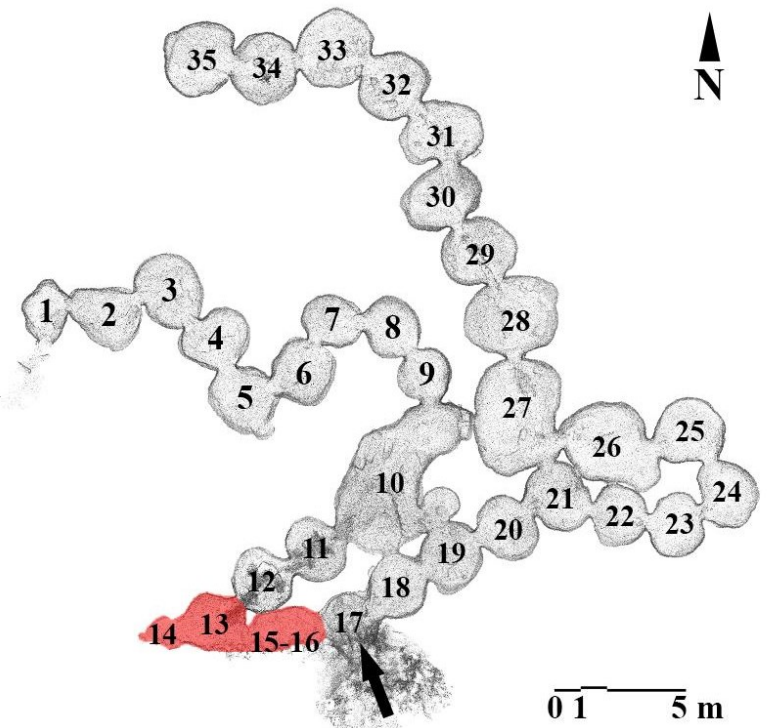

Figure 5. BLK2GO point cloud. In red the rooms not previously surveyed.

Figure 6 shows the overlap between the orthophoto obtained by the integrated numerical model P30-BLK2GO and the graphical restitution of of Guzzardi's publicstion. This makes it possible to verify any variations from the only edited graphic representation of the site. An initial objective visual comparison between the two representations reveals a wrong interpretation of rooms 14 , 15 and 16, due to the difficulty of accessing them and a difference in the orientation of the rooms 1-9 and 30-30, as well as some dimensional imprecision.

This comparison gives rise to a thorough reflection on the survey topics, which will be explored in further research steps. On the one hand, the traditional survey strongly based on the precious and undisputed interpretative ability of the surveyor/scholar, skilfully rendered in a high quality graphic representation, that responds to precise scientific documentation requirements; on the other hand, the 3D digital survey, which is also strongly influenced on the organizational and interpretative abilities of the surveyor/scholar and which allows to respond to different requests and to stimulate new research purposes.

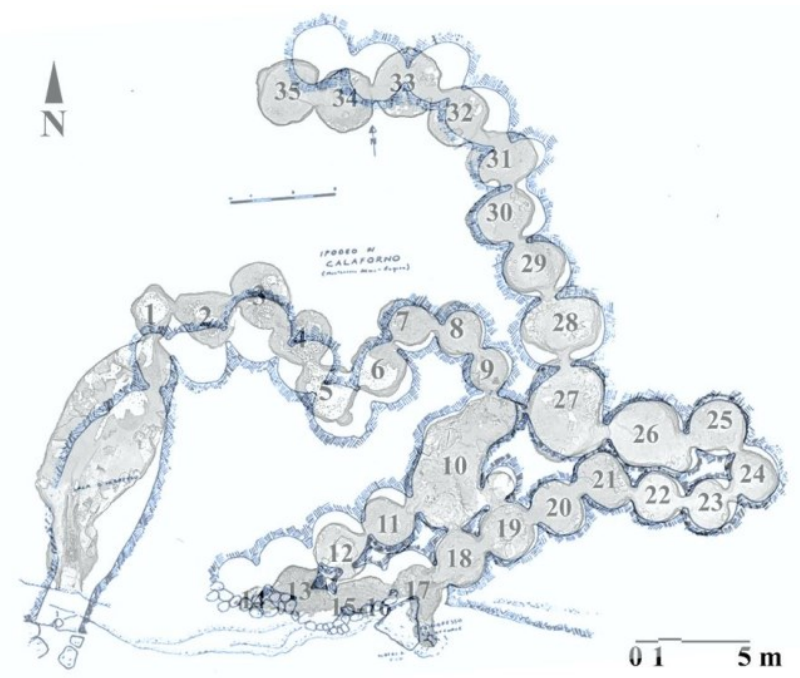

Figure 6. Overlap between the orthophoto, in grey, obtained by P30-BLK2GO final point cloud (2021) and, in blu, twodimensional representation of Guzzardi (1980).

\section{RESULTS}

Three different point clouds were obtained from this research work: the P30 point cloud of rooms 1 to 35 (excluding rooms 13, $14,15-16$ ), the BLK2GO point cloud of rooms 1 to 35 , and the GoPro point cloud of room 23 (SfM survey). To georeference the P30 numerical model representing the ground-truth TLS point cloud, six geodetic ground control points were also set around the open air scanned area and premeasured using the Leica GS18 GNSS-RTK. The visual alignment of Leica Geosystem's Cyclone software was instead used to ensure the BLK2GO point cloud had the same reference system as the P30 model.

Some metric and visual analyses are proposed for comparative purposes. The first assessment concerns the entire underground environment. The accuracy and the reliability of the P30 and BLK2GO models were evaluated through a comparative analysis of the different point cloud data acquired in terms of point quantity, point density, restitution scale, noise level, acquisition and processing time, and weight, as shown in Table 1. For the BLK2GO mobile laser, acquisition time is derived from the sum of the initialization phase time, the acquisition path, and the closure process. For the P30 TLS, it is the sum of the instrument stationing time and the acquisition phase, multiplied by the total number of acquisition locations.

Processing time covers the timing of registration in a unique reference system of the different point clouds acquired, plus possible filtering, decimation and meshing phases.

\begin{tabular}{|l|c|c|}
\hline & P30 & BLK2GO \\
\hline Points number & $\approx 230 \mathrm{million}$ & $\approx 4,8$ million \\
Points density & High & Low \\
Restitution scale & $1: 20$ & $1: 100$ \\
Noise level & Low & High \\
Acquisition time & $12 \mathrm{~h}$ & $24 \mathrm{~min}$ \\
Processing time & $8 \mathrm{~h}$ & $30 \mathrm{~min}$ \\
Weight (.e57) & $6550 \mathrm{MB}$ & $94,4 \mathrm{MB}$ \\
\hline
\end{tabular}

Table 1. Comparison between P30 and BLK2GO point clouds.

All metric comparisons were performed with the CloudCompare open-source software using the Cloud-to-Cloud algorithm (C2C), which allows measurement of the metric deviation between two clouds. The P30 point cloud was chosen as the reference cloud because it is characterized by higher accuracy. The comparison began by analyzing the global accuracy of the entire point cloud to also check for possible drift errors (Figure 7), and then on a portion of the same point cloud.

The global comparison shows that most deviations range from 3 $\mathrm{mm}$ to $2 \mathrm{~cm}$ (blue and green points). Larger deviations (red points) occur in two cases where the P30 point cloud is missing and where the morphology has changed in the two years between the two scans due to excavations and the removal of boulders. Figure 8 shows a $1 \mathrm{~cm}$ thick slice of an area encompassing the rooms arranged in a ring shape around Room 26. In this representative portion of the site, a maximum value of $1.75 \mathrm{~cm}$ and a minimum value of $0.99 \mathrm{~cm}$ are found.

As already mentioned, the photogrammetric survey of room 23 was conducted to test the methodology in one of the Hypogeum's smallest rooms and to try to obtain a model with faithful RGB values.

Figure 9 shows the quantitative and qualitative density variation between the P30, BLK2GO and GoPro point clouds. Instead, Figures 10 and 11 provide a blue-red colour scale for the $\mathrm{C} 2 \mathrm{C}$ analyses between the P30 and BLK2GO point clouds and between the $\mathrm{P} 30$ and GoPro point clouds, respectively. 


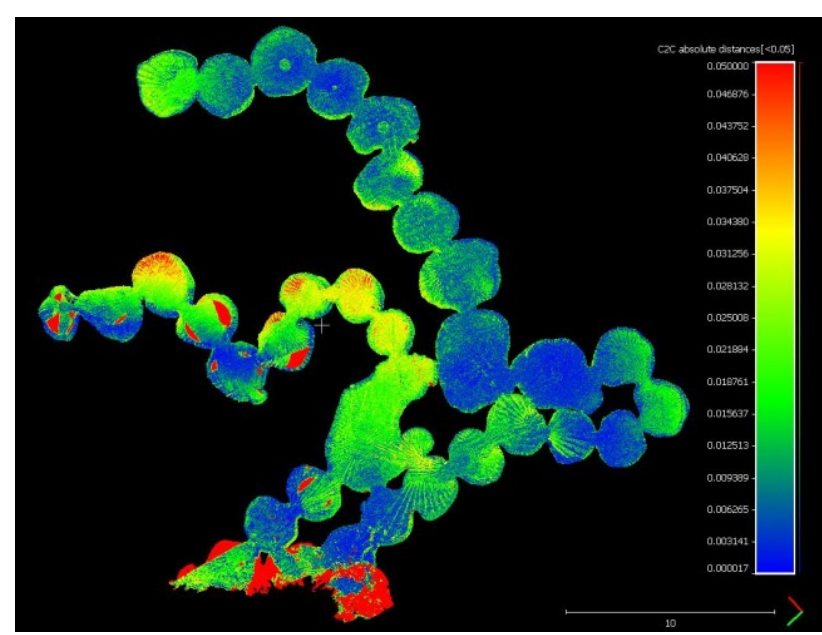

Figure 7. C2C analyses P30-BLK2GO point clouds (calculation range: $0.00-0.02 \mathrm{~m}$ ).

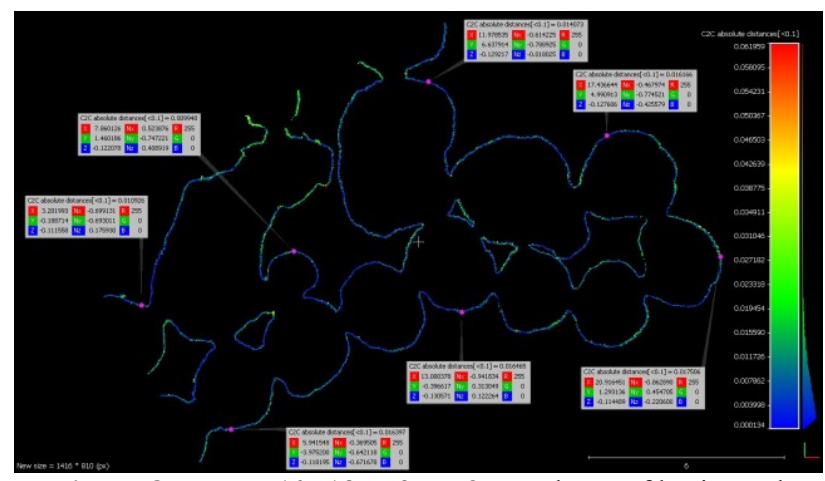

Figure 8. Rooms 10 -18 to 27: C2C analyses of horizontal slices between the $\mathrm{P} 30$ and BLK2GO point clouds

(calculation range: 0.00-0.02 m).

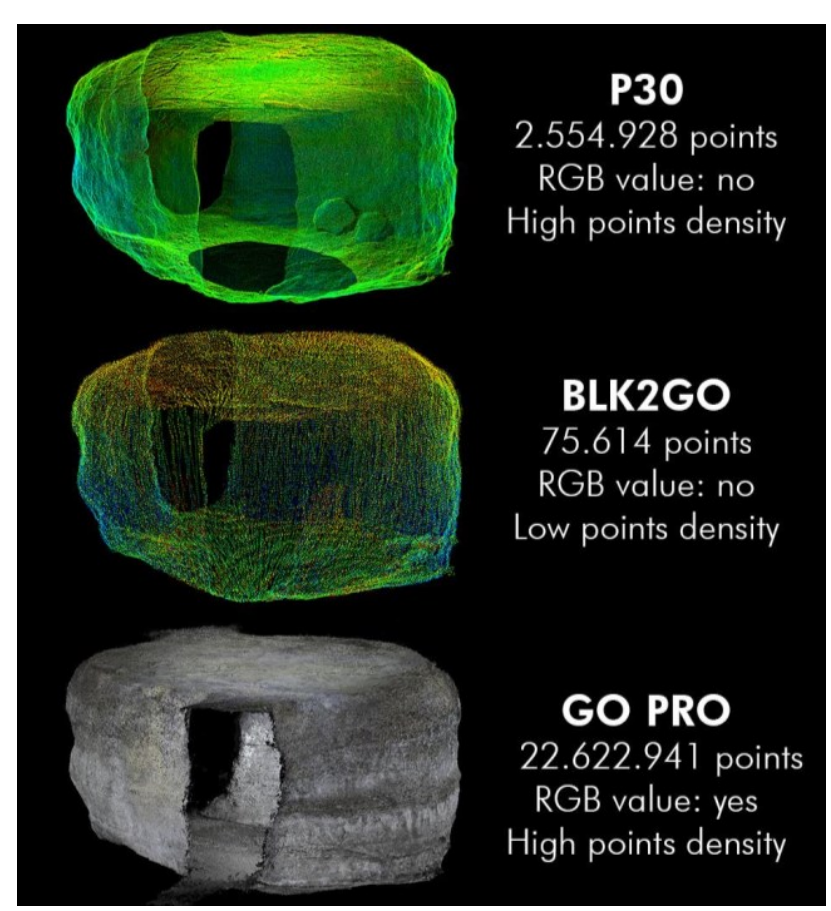

Figure 9. Room 23: variation of the points cloud density.

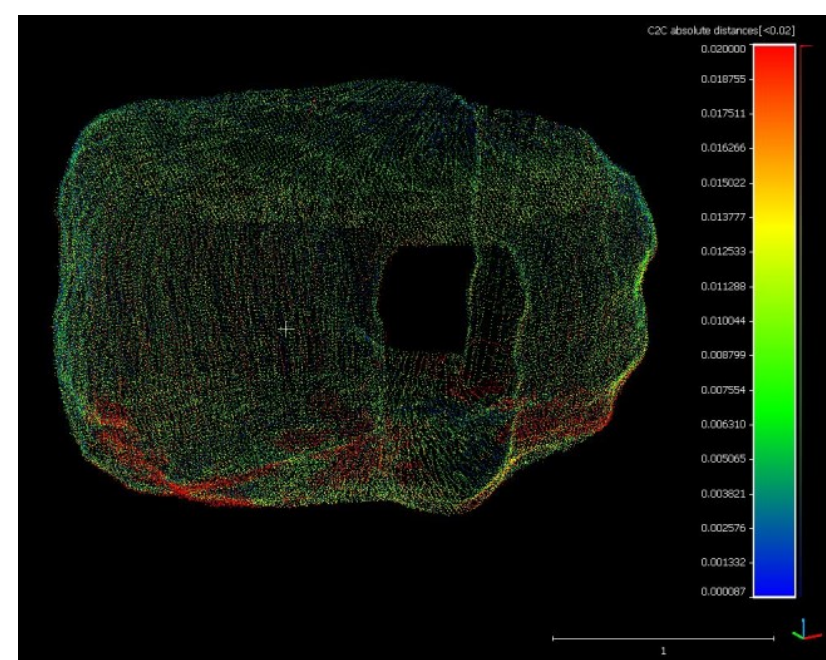

Figure 10. Room 23: $\mathrm{C} 2 \mathrm{C}$ analyses between the $\mathrm{P} 30$ and BLK2GO point clouds (calculation range: $0.00-0.02 \mathrm{~m}$ ).

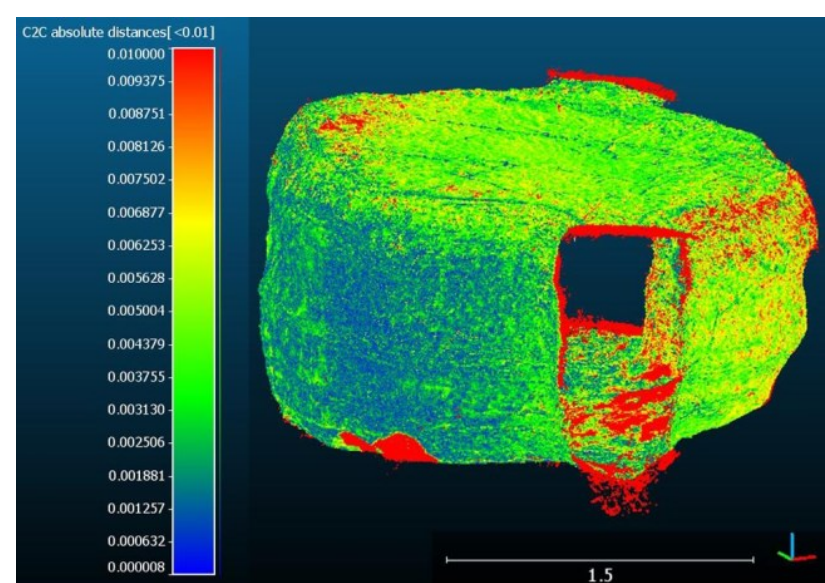

Figure 11. Room 23: $\mathrm{C} 2 \mathrm{C}$ analyses between the $\mathrm{P} 30$ and GoPro point clouds (calculation range: $0.00-0.01 \mathrm{~m}$ ).

\section{CONCLUSIONS}

From these metric and visual analyses, it can be observed that the application of SLAM technology lends itself to the complex morphology of the Hypogeum in terms of acquisition and post processing times of the metric data. For the identification of geological features like traces due to the infiltration of water in the ceiling and on the slightly curved walls, it is certainly more advisable to use digital surveying technologies like TLS and SFM, which generate more detailed restitutions.

From an archaeological perspective, the results of this research suggest real opportunities for more sustainable and affordable procedures in field excavations. Digitisation is becoming an increasingly important aspect of archaeological practice. However, if the importance of 3D survey is widely accepted today, the elaboration of reliable 3D models remains limited to single, important, case studies with adequate funding. The expenditure in terms of time and cost relegate digitisation outside of routine research activities, especially on minor archaeological areas or emergency excavations, where, paradoxically, 3D surveys would provide unique opportunities for the quick and effective acquisition of critical data.

Through the global verification of TLS and SLAM model reliability, we maintain that such research can contribute to enriching the protocols surrounding the archaeological investigation of sites characterized by complex morphology, 
irregular surfaces, narrow spaces, specific chromatic features, scarce or total absence of illumination, and physical obstacles.

\section{AUTHOR CONTRIBUTIONS}

Introduction: G.D., M.F.; Related works: G.R.; Case Study: M.F.; Methodology: G.D.; Digital survey and processing: G.D.; Results: G.D., G.R.; Conclusions: M.G., P.M.M.

\section{ACKNOWLEDGEMENTS}

The research was partly funded by the project PON ARS01_00926 eWAS - An Early Warning System for Cultural Heritage - PNR 2015-2020. The scientific director is Prof Vincenzo Sapienza (Department of Civil Engineering and Architecture, University of Catania), and the responsible for onsite research activities is Prof. Pietro Militello (Department of Human Sciences, University of Catania).

Excavation activities in 2017-18 were conducted under Project Mneme, Costruzione del passato e pratiche della memoria nel Mediterraneo, Bando Prometeo Linea 3, University of Catania, cataloguing and digitization activities in 2020-21, under the project Storage: dai dati al Web, programma Pia.Ce.Ri., University of Catania.

The 2017-19 and 2020 survey with the Leica P30 laser scanner was performed with the technical contribution of Antonio and Salvatore Garro (3D Dimension Company, Catania, Italy). The BLK360 laser scanner used for the 2021 survey is a equipment of the Laboratory of Architectural Photogrammetry and Surveying "Luigi Andreozzi", section of the RDA Laboratory DICAR - University of Catania (Person in charge: Prof.ssa Mariateresa Galizia). The survey with the BLK2GO laser scanner and the point cloud georeferencing was performed with the technical contribution of Nicolò di Blasi (Sales Agent of Leica Geosystem) and Rosario Caruso (Technical Advisor of Leica Geosystem).

\section{REFERENCES}

Aiello, D., Basso, A., Spena, M.T., D’Agostino, G., Montedoro, U., Galizia, M., Grasso, R., Santagati, C., 2019: The Virtual Batcave: a project for the safeguard of a UNESCO WHL fragile ecosystem. Int. Arch. Photogramm. Remote Sens. Spatial Inf. Sci., XLII-2/W9, 17-24. doi.org/10.5194/isprs-archives-XLII-2W9-17-2019.

Alessandri, L., Baiocchi, V., Del Pizzo, S., Di Ciaccio F., Onori, M., Rolfo, M. F., Troisi, S., 2020: A flexible and swift approach for 3D image-based survey in a cave. Appl. Geomat. doi.org/10.1007/s12518-020-00309-4.

Chiabrando F., Della Coletta C., Sammartano G., Spanò A., Spreafico A., 2018: "Torino 1911" project: a contribution of a SLAM-based survey to extensive 3D heritage modeling. Int. Arch. Photogramm. Remote Sens. Spatial Inf. Sci., XLII-2, 225234. doi.org/10.5194/isprs-archives-XLII-2-225-2018.

Clini, P., Nespeca, R., Angeloni, R., and Mammoli, R., 2019: The integrated survey of narrow spaces and underground architecture: the case study of Campana Cave bas-reliefs. Int. Arch. Photogramm. Remote Sens. Spatial Inf. Sci., XLII-2/W9, 277282. doi.org/10.5194/isprs-archives-XLII-2-W9-277-2019.

D’Agostino, G., Figuera, M., Rodonò, G., 2021a: Digital survey and reception structures for a virtual fruition: the case study of the Hypogeum of Calaforno (Ragusa). ARQUEOLÓGICA 2.0 9th International Congress \& 3rd GEORES - GEOmatics and pREServation, Valencia, 569-572.

D’Agostino, G., Figuera, M., Pennisi, V., Russo, G., Sanfilippo, M., Militello, P. M., and Musumeci, R. E., 2021b: Hydraulic risk assessment in archaeological sites supported by an integrated digital survey - CFD (Computational Fluid Dynamics) monitoring approach. Int. Arch. Photogramm. Remote Sens. Spatial Inf. Sci., XLVI-M-1-2021, 155-163, doi.org/10.5194/isprs-archives-XLVI-M-1-2021-155-2021.

Dell'Amico A., 2021: Mobile Laser Scanner mapping system's for the efficiency of the survey and representation processes. Int. Arch. Photogramm. Remote Sens. Spatial Inf. Sci., XLVI-M-12021, 199-205, doi.org/10.5194/isprs-archives-XLVI-M-12021-199-2021.

Di Stefano, F., Torresani, A., Farella, E.M., Pierdicca, R., Menna, F., Remondino, F., 2021: 3D Surveying of Underground Built Heritage: Opportunities and Challenges of Mobile Technologies. Sustainability, 13, 13289, doi.org/10.3390/su132313289.

Ebolese, D., Lo Brutto, M., Dardanelli, G., 2019: The integrated 3D survey for underground archeological environment. Int. Arch. Photogramm. Remote Sens. Spatial Inf. Sci., XLII-2/W9, 311317. doi.org/10.5194/isprs-archives-XLII-2-W9-311-2019.

Figuera, M., 2018: Patrimonio diffuso, comunità locali. La "riscoperta": per una ipotesi di valorizzazione innovativa dell'ipogeo di Calaforno. Archivio Storico per la Sicilia Orientale, 2018(1), 5-23. doi.org/10.3280/ASSO2018-001001.

Figuera, M., (in press): Sicilian Landscape and A-structural Architecture from Survey to Virtual Reconstruction: the case of the Calaforno Hypogeum. In D. Panagiotopoulos \& P.M. Militello (Eds.), Modelling Archaeological Landscapes.

Giordan, D.; Godone, D.; Baldo, M.; Piras, M.; Grasso, N.; Zerbetto, R., 2021: Survey Solutions for 3D Acquisition and Representation of Artificial and Natural Caves. Appl. Sci., 11, 6482. doi.org/10.3390/app11146482.

Guzzardi, L. 1980: Un ipogeo preistorico a Calaforno e il suo contesto topografico. Sicilia Archeologica, 42, 67-94.

La Russa, F. M., Galizia, M., and Santagati, C., 2021: Remote sensing and city information modeling for revealing the complexity of historical centers. Int. Arch. Photogramm. Remote Sens. Spatial Inf. Sci., XLVI-M-1-2021, 367-374, doi.org/10.5194/isprs-archives-XLVI-M-1-2021-367-2021.

Mandelli, A., Fassi, F., Perfetti, L., and Polari, C., 2017: Testing different survey techniques to model architectonic narrow spaces. Int. Arch. Photogramm. Remote Sens. Spatial Inf. Sci., XLII-2/W5, 505-511, doi.org/10.5194/isprs-archives-XLII-2W5-505-2017.

Militello, P.M., 2021: Calaforno I. Le indagini 2013-2017. Archaeopress, Oxford.

Militello, P.M., Di Stefano, G. 2015: Calaforno (Giarratana, Prov. di Ragusa). Indagini 2013-2014. Notiziario di Preistoria e Protostoria 2(II), 63-65.

Militello, P.M., Sammito, A.M., Scerra, S., 2018: Calaforno (Giarratana, RG). Notiziario di Preistoria e Protostoria 5(II), 9093

Pace, G., 2019: Underground Built Heritage as catalyser for Community Valorisation. Underground4value. In Proceedings of the 55th ISOCARP (International Society of City and Regional Planners), World Planning Congress, Jakarta-Bogor, Indonesia, 9-13 September 2019, pp. 1250-1260.

Perfetti, L., Polari, C., Fassi, F., Troisi, S., Baiocchi, V., Del Pizzo S., Giannone, F., Barazzetti, L., Previtali, M., Roncoroni, F., 2018: Fisheye Photogrammetry to Survey Narrow Spaces in Architecture and a Hypogea Environment. In Latest 
Developments in Reality-Based $3 D$ Surveying and Modelling; Remondino, F., Georgopoulos, A., González-Aguilera, D., Agrafiotis, P., Eds.; MDPI: Basel, Switzerland pp. 3-28. DOI: 10.3390/books978-3-03842-685-1-1.

Piniotis, G., Soile, S., Bourexis, F., Tsakiri, M., and Ioannidis, C. 2020: Experimental assessment of 3D narrow space mapping technologies. Int. Arch. Photogramm. Remote Sens. Spatial Inf. Sci., XLIII-B2-2020, 149-156, doi.org/10.5194/isprs-archivesXLIII-B2-2020-149-2020

Pukanská, K., Bartoš, K., Bella, P., Gašinec, J., Blistan, P., Kovanič, L., 2020: Surveying and High-Resolution Topography of the Ochtiná Aragonite Cave Based on TLS and Digital Photogrammetry. Appl. Sci., 10(13), 4633. doi.org/10.3390/app10134633.

Rodríguez-Gonzálvez, P., Nocerino, E., Menna, F., Minto, S., and Remondino, F., 2015: 3D surveying \& modeling of underground passages in WWI fortifications. Int. Arch. Photogramm. Remote Sens. Spatial Inf. Sci., XL-5/W4, 17-24. doi.org/10.5194/isprsarchives-XL-5-W4-17-2015.

Salgues, H., Macher, H., and Landes, T., 2020: Evaluation of mobile mapping systems for indoor surveys. Int. Arch. Photogramm. Remote Sens. Spatial Inf. Sci., XLIV-4/W1-2020, 119-125, doi.org/10.5194/isprs-archives-XLIV-4-W1-2020$119-2020$

Sammartano, G., Spanò, A., 2018: Point clouds by SLAM-based mobile mapping systems: accuracy and geometric content validation in multisensor survey and stand-alone acquisition. Appl Geomat 10, 317-339 . doi.org/10.1007/s12518-018-02217.

Saulli, T., Wahbeh, W., Nardinocchi, C., 2018: 3D survey and digital models as the first documentation of Hypogeum of S. Saba in Rome. Appl. Geomat., Vol. 10, Issue 4, pp. 377-384. doi.org/10.1007/s12518-018-0244-0.

Tanasi, D., Hassam, S., Kingsland, K., 2021: Underground Archeology: Photogrammetry and Terrestrial Laser Scanning of the Hypogeum of Crispia Salvia (Marsala, Italy). Pattern Recognition. ICPR International Workshops and Challenges, pp. 353-367. doi.org/10.1007/978-3-030-68787-8_27.

Teppati Losè L., Chiabrando F., Novelli F., Patrucco G., Perri S., 2021: Documentation of a complex Cultural Heritage asset with integrated geomatic survey: the Montanaro bell tower. ARQUEOLÓGICA 2.0 - 9th International Congress \& $3 \mathrm{rd}$ GEORES - GEOmatics and pREServation, Valencia, 177-184.

Tucci, G., Bonora, V., Conti, A., Fiorini, L., 2017. Digital workflow for the acquisition and elaboration of $3 \mathrm{D}$ data in a monumental complex: the fortress of Saint John the Baptist in Florence. In: ISPRS - International Archives of the Photogrammetry, Remote Sensing and Spatial Information Sciences, XLII-2/W5, 679-686.

https:// doi.org/10.5194/isprsarchives-XLII-2-W5-679-2017.

Tucci, G., Visintini, D., Bonora, V., Parisi, E., 2018. Examination of Indoor Mobile Mapping Systems in a Diversified Internal/External Test Field. Applied Sciences, 8(3), 401. https://doi.org/10.3390/app8030401. 